Research Journal of Medical Sciences 5 (3): 145-149, 2011

ISSN: $1815-9346$

(C) Medwell Journals, 2011

\title{
Effect of Frequent Self-Monitoring of Blood Glucose on HbA1c Level Among Type 2 Diabetic Patients
}

\author{
${ }^{1}$ Selwa Elias Yacoub, ${ }^{2}$ Miaad Hana Mansur and ${ }^{1}$ Yousif Abdul Raheem \\ ${ }^{1}$ Department of Community Medicine, \\ Al Kindy College of Medicine, University of Baghdad, Baghdad, Iraq \\ ${ }^{2}$ Specialization Center of Endocrinology and Diabetes, University of Baghdad, Baghdad, Iraq
}

\begin{abstract}
Self-Monitoring of Blood Glucose (SMBG) is an integral part of management of type 2 diabetes mellitus on insulin and oral agents. SMBG is an important adjunct to HbAlc which is a standard assessment of glycemia. To evaluate the effectiveness of frequent use of SMBG on the level of HbAlc among type 2 diabetic patients. Across sectional study had been conducted at the specialized Center of Endocrinology and Diabetes for the period from October 2009 till August 2010. A convenient sample of 126 type 2 diabetic patients attending the center had been enrolled. The participants were classified into 3 groups according to the frequency of using SMBG, the demographic characteristic, Body Mass Index (BMI), duration of diabetes mellitus, line of treatment and the mean level of HbAlc of all participants had been assessed. No statistical differences had been found in the demographic characteristic, BMI duration of diabetes mellitus, line of treatment and the mean level of HbAlc among the three studied groups. Participants of secondary and higher education were more frequently use SMBG. Neither Patients on oral hypoglycemic drugs nor those on a regimen include insulin show differences in their $\mathrm{HbAl} \mathrm{c}$ in relation to frequency of SMBG use. Use of SMBG regardless of it's frequency among type 2 diabetic patients was not beneficial to achieve a better glycemic control as monitored by the level of HbAlc, optimization of it's effectiveness may require advanced facility for better interpretation and response adapted by the patients and doctors.
\end{abstract}

Key words: SMBG, HbAlc, type 2 diabetes mellitus, glycemic control, patients, Iraq

\section{INTRODUCTION}

Diabetes is a significant and growing worldwide health concerns. People with diabetes are at increased risk for developing numerous complications resulting in increased health care costs. Blood glucose control is critical for managing diabetes and to reduce the development and/or progression of microvascular and macrovascular complications (Parkin and Davidson, 2009; Davis et al., 2006).

The American Diabetes Association recommends Self-Monitoring (SMBG) as an integral part of diabetes management for patients who are treated with insulin and as a useful component for achieving glycemic goals for patients use oral medications or medical nutrition (American Diabetes Association, 2007) in addition patients with diabetes should have a glycated heamoglobin $(\mathrm{HbAlc})$ measurement at least two times a year (American Diabetes Association, 2007) so both measurements are essential for standard assessment of glycemic control (American Diabetes Association, 2002; Palmer et al., 2006).
All diabetic patients attending SCED taught to use SMBG as part of the educational program adapted by the center and their HbAl mostly measured every 6 months.

$\mathrm{HbAlc}$ reflects mean blood glucose levels in over the previous 2-3 months (Derr et al., 2003). While Self assessment of Blood Glucose (SMBG) provides information immediately on the actual blood glucose levels at the time of testing (Palmer et al., 2006) and permits the well informed and motivated patients to make appropriate adjustments in treatment (particularly in insulin dose) on a day to day basis. It also reveal patterns of changes in blood glucose throughout the day and document hypo or hyperglycemia (American Diabetes Association, 2002).

Self Monitoring of Blood Glucose (SMBG) has become a principle component of diabetes management particularly in insulin treated patients (Parkin and Davidson, 2009) though it's efficacy independent of other self management practices is still uncertain (Adams et al., 2003) and no studies either experimental or observational have addressed the long term impact of various SMBG testing frequencies on glycemic control (Karter et al., 2006).

Corresponding Author: Selwa Elias Yacoub, Department of Community Medicine, Al Kindy College of Medicine, University of Baghdad, Baghdad, Iraq 
This study had been conducted to explore the beneficial effect of frequent use of SMBG on glycemic control among Type 2 diabetes revealed by its relevance to the level of $\mathrm{HbAl} \mathrm{c}$.

\section{MATERIALS AND METHODS}

A cross sectional study had been conducted at the Specialized Center of Endocrinology and Diabetes (SCED) in Baghdad for the period from October 2009 till August 2010. A convenient sample of 126 diabetic patients attending this center were enrolled.

\section{Inclusion criteria:}

- Type 2 diabetes mellitus

- Registered at the SCED for at least 6 months ago

- Being restricted to the specified line of treatment for the last 6 months

- Initiate using $\mathrm{SMBG}$ at least 6 months prior to the time of participation in the study (for SMBG user's)

- Can recall the frequency of using SMBG

All participants had completed through an interview, a unique questioner to address their age, sex, educational status, duration of Diabetes Mellitus (DM) and line of treatment. Patients were defined according to their educational status into three levels, primary, secondary and higher education.

Initially stratification of the studied sample was done according to the line of treatment into 3 strata; no medication (diet controlled only), Oral Hypoglycemic Drug $(\mathrm{OHD})$ and insulin (either alone or any other regimen that includes insulin) (Karter et al., 2006).

The frequency of using SMBG had been assessed depending on the recall information of practicing it during the last 6 months before the interview and accordingly the participants were classified into 3 main studied groups; group 1 using it one or more times per week, group 2 $<1$ time week ${ }^{-1}$ and group 3 never use it (Davis et al., 2006).

Duration of Diabetes Mellitus (DM) was calculated in years (the lowest duration being $1 / 2$ year) and accordingly the included patients were divided into 3 categories; $<5$ years between $5-10$ years and $>10$ years duration.

Anthropometric measurements had been done for each patient, weight measured with their indoor clothing using a digital weight scale (Seca, Austeralia) and calculated to the nearest fraction of $\mathrm{kg}$ while height was measured in standing position without shoes using CMS weighing equipment LTD. Body Mass Index (BMI) then calculated by dividing weight $(\mathrm{kg})$ by height $\left(\mathrm{m}^{2}\right)$.
Level of HbAlc had been measured for all the participants being achieved by the laboratory of SCED using liquid chromatography. All data was introduced into a personal computer and analyzed using Minitab version $13, \chi^{2}$-test was used for interpretation of discrete data while ANOVA test was applied for mean analysis of continuous data. The $\mathrm{p}<0.05$ was the level of significance in this study.

\section{RESULTS AND DISCUSSION}

Among 126 diabetic patients participating in this study (Table 1) being classified according to the frequency of using SMBG into three main groups, 64 $(50.80 \%)$ were in group 1 using it one or more times weekly, $28(22.22 \%)$ found to be in group 2 using it less than one time weekly and $34(26.98 \%)$ were in group 3 never using it. An overall users of $92(72.02 \%)$ patients.

No significant statistical differences had been found in the demographic characteristic of the patients among the three groups regarding their gender $(p=0.455)$, mean age $(p=0.054)$ and mean BMI $(p=0.957)$. The only statistical differences found to be related to their educational level $(\mathrm{p}=0.008)$.

Table 1: Demographic characteristic, BMI, duration of D.M, line of treatment and level of $\mathrm{HbA} 1 \mathrm{c}$ in relation to frequency of using SMBG

\begin{tabular}{|c|c|c|c|c|c|}
\hline \multirow[b]{2}{*}{ Variables } & \multicolumn{5}{|c|}{ Frequency of SMBG } \\
\hline & $\begin{array}{l}\text { Group } 1^{*} \\
\mathrm{n}=64\end{array}$ & $\begin{array}{l}\text { Group } 2 * * \\
\mathrm{n}=28\end{array}$ & $\begin{array}{l}\text { Group } 3^{\text {**** }} \\
\mathrm{n}=34\end{array}$ & $\begin{array}{l}\text { Total } \\
n=126\end{array}$ & p-value \\
\hline Male & 29.000 & 16.000 & 19.000 & 64.000 & - \\
\hline Female & 35.000 & 12.000 & 15.000 & 62.000 & 0.455 \\
\hline \multicolumn{6}{|l|}{ Age } \\
\hline Mean & 42.440 & 36.570 & 45.290 & 41.580 & - \\
\hline $\mathrm{SD}$ & 14.480 & 12.000 & 15.260 & 13.480 & 0.054 \\
\hline Min. & 18.000 & 20.000 & 19.000 & 18.000 & - \\
\hline Max. & 78.000 & 68.000 & 81.000 & 81.000 & - \\
\hline \multicolumn{6}{|l|}{ Education } \\
\hline Primary & 12.000 & 9.000 & 13.000 & 34.000 & - \\
\hline Secondary & 26.000 & 16.000 & 16.000 & 58.000 & 0.008 \\
\hline Higher & 26.000 & 3.000 & 5.000 & 34.000 & - \\
\hline \multicolumn{6}{|l|}{ BMI } \\
\hline Mean & 27.080 & 27.030 & 27.370 & 27.050 & - \\
\hline SD & 5.129 & 6.560 & 4.440 & 4.970 & 0.957 \\
\hline Min. & 16.300 & 18.600 & 20.300 & 16.300 & - \\
\hline Max. & 40.440 & 37.500 & 36.250 & 40.440 & - \\
\hline \multicolumn{6}{|c|}{ Duration of DM (years) } \\
\hline$<5$ & 16.000 & 8.000 & 12.000 & 36.000 & 0.865 \\
\hline $5-10$ & 26.000 & 11.000 & 11.000 & 48.000 & - \\
\hline$>10$ & 22.000 & 9.000 & 11.000 & 42.000 & - \\
\hline \multicolumn{6}{|l|}{ Treatment } \\
\hline $\mathrm{OHD}$ & 12.000 & 7.000 & 9.000 & 28.000 & - \\
\hline Insulin $†$ & 52.000 & 21.000 & 25.000 & 98.000 & 0.629 \\
\hline \multicolumn{6}{|l|}{ HbAIc 1} \\
\hline Mean & 6.622 & 7.164 & 6.865 & 7.013 & - \\
\hline $\mathrm{SD}$ & 1.192 & 1.290 & 1.307 & 1.231 & 0.551 \\
\hline Min. & 4.900 & 5.800 & 4.900 & 4.900 & - \\
\hline Max. & 10.000 & 10.500 & 9.400 & 10.500 & - \\
\hline
\end{tabular}


Res. J.Med. Sci., 5 (3): 145-149, 2011

Table 2: Mean level of HbAlc in association to the frequency of SMBG and educational level

\begin{tabular}{|c|c|c|c|c|}
\hline \multirow[b]{2}{*}{ Level of education } & \multicolumn{3}{|c|}{ Frequency of SMBG } & \multirow[b]{2}{*}{$\mathrm{p}$ value } \\
\hline & $\begin{array}{l}\text { Group } 1 \\
\mathrm{n}=64\end{array}$ & $\begin{array}{l}\text { Group } 2 \\
\mathrm{n}=28\end{array}$ & $\begin{array}{l}\text { Group } 3 \\
\mathrm{n}=34\end{array}$ & \\
\hline \multicolumn{5}{|l|}{ Primary } \\
\hline No & 12.000 & 9.000 & 13.000 & - \\
\hline \multicolumn{5}{|l|}{ HbAIc 1} \\
\hline Mean & 7.050 & 7.367 & 6.975 & - \\
\hline $\mathrm{SD}$ & 1.746 & 1.577 & 0.754 & 0.389 \\
\hline \multicolumn{5}{|l|}{ Secondary } \\
\hline No & 26.000 & 16.000 & 16.000 & - \\
\hline \multicolumn{5}{|l|}{ HbAIc 1} \\
\hline Mean & 6.625 & 6.714 & 6.880 & - \\
\hline $\mathrm{SD}$ & 0.948 & 0.267 & 1.197 & 0.974 \\
\hline \multicolumn{5}{|l|}{ Higher } \\
\hline No & 26.000 & 3.000 & 5.000 & - \\
\hline \multicolumn{5}{|l|}{ HbAIc 1} \\
\hline Mean & 6.463 & 6.238 & 6.713 & - \\
\hline $\mathrm{SD}$ & 1.128 & 0.858 & 1.441 & 0.541 \\
\hline pvalue & 0.376 & 0.046 & 0.931 & - \\
\hline
\end{tabular}

The three groups showed no differences in relation to the duration of D.M $(\mathrm{p}=0.865)$. Non of the participants found to be assigned to medical diet alone as one of the lines of treatment of type 2 diabetes and ultimately 2 subdivision only had been identified, 28 (22.22\%) receiving Oral Hypoglycemic Drug $(\mathrm{OHD})$ and $98(77.78 \%)$ found to be on insulin (either alone or any other regimen that includes insulin), no differences had been found between the main three studied groups in relation to their line of treatment $(\mathrm{p}=0.629)$.

The mean level of HbAlc did not reveal any statistical differences between the three studied groups in association to the frequency of using $\operatorname{SMBG}(\mathrm{p}=0.551)$.

The only significant statistical differences in the level of within the three main groups of the studied sample considering their educational level (Table 2) found within group 2 (using SMBG $<1$ times weekly) $(\mathrm{p}=0.046$ ) while no significant differences was found in between them accordingly.

No significant differences was found in the mean level of HbAlc in between participants of the three groups (Table 3 ) in relation to the duration of DM, the only significant differences $(\mathrm{p}=0.005)$ within group 2 , those using SMBG less than once weekly.

The three main studied groups show no statistical differences in the mean level of HbAlc (Table 4) in between or within them in relation to the line of treatment being on $\mathrm{OHD}$ or on insulin containing regimen.

The utility of SMBG reported by $72.03 \%$ of type 2 diabetic patients in the present sample found to be similar to the results of a Fermantal diabetes study conducted at Austeralia 2006 (Davis et al., 2006) being 70\%, revealing the awareness among diabetic patients attending the SCED to the importance of individual monitoring of blood glucose and addressing the availability and affordability
Table 3: Mean level of HbA1c in association to frequency of SMBG and duration of DM

\begin{tabular}{|c|c|c|c|c|}
\hline \multirow[b]{2}{*}{ Duration DM (y ears) } & \multicolumn{3}{|c|}{ Frequency of SMBG } & \multirow[b]{2}{*}{$\mathrm{p}$ value } \\
\hline & $\begin{array}{l}\text { Group } 1 \\
\mathrm{n}=64\end{array}$ & $\begin{array}{l}\text { Group 2 } \\
\mathrm{n}=28\end{array}$ & $\begin{array}{l}\text { Group } 3 \\
\mathrm{n}=34\end{array}$ & \\
\hline \multicolumn{5}{|l|}{$<5$} \\
\hline No & 16.000 & 8.000 & 12.000 & - \\
\hline \multicolumn{5}{|l|}{ HbAIc 1} \\
\hline Mean & 6.518 & 6.740 & 6.829 & - \\
\hline $\mathrm{SD}$ & 1.027 & 0.704 & 1.383 & 0.546 \\
\hline \multicolumn{5}{|l|}{$5-10$} \\
\hline No & 26.000 & 11.000 & 11.000 & - \\
\hline \multicolumn{5}{|l|}{ HbAIc 1} \\
\hline Mean & 6.682 & 8.429 & 6.844 & - \\
\hline SD & 1.505 & 1.946 & 1.346 & 0.950 \\
\hline \multicolumn{5}{|l|}{$>10$} \\
\hline No & 22.000 & 9.000 & 11.000 & - \\
\hline \multicolumn{5}{|l|}{ HbAIc 1} \\
\hline Mean & 6.944 & 6.714 & 6.840 & - \\
\hline SD & 1.267 & 0.267 & 1.081 & 0.901 \\
\hline $\mathrm{p}$-value & 0.617 & 0.005 & 0.982 & - \\
\hline
\end{tabular}

Table 4: Mean level of $\mathrm{HbA1c}$ in association with frequency of SMBG and line of treatment

\begin{tabular}{|c|c|c|c|c|}
\hline \multirow[b]{2}{*}{ Line of treatment } & \multicolumn{3}{|c|}{ Frequency of SMBG } & \multirow[b]{2}{*}{ p value } \\
\hline & $\begin{array}{l}\text { Group } 1 \\
\mathrm{n}=64\end{array}$ & $\begin{array}{l}\text { Group } 2 \\
\mathrm{n}=28\end{array}$ & $\begin{array}{l}\text { Group } 3 \\
\mathrm{n}=34\end{array}$ & \\
\hline \multicolumn{5}{|l|}{$\overline{\mathrm{OHD}}$} \\
\hline No & 12.000 & 7.000 & 9.000 & 0.86 \\
\hline \multicolumn{5}{|l|}{ HbAlc } \\
\hline Mean & 6.660 & 6.860 & 6.580 & - \\
\hline $\mathrm{SD}$ & 0.940 & 0.950 & 1.330 & - \\
\hline \multicolumn{5}{|l|}{ Insulin } \\
\hline No & 52.000 & 21.000 & 25.000 & 0.73 \\
\hline \multicolumn{5}{|l|}{ HbAlc } \\
\hline Mean & 6.790 & 7.270 & 6.780 & - \\
\hline SD & 1.470 & 1.530 & 1.560 & - \\
\hline $\mathrm{p}$-value & 0.714 & 0.570 & 0.862 & ـ \\
\hline
\end{tabular}

of glucose meters and strips for them. Also it may reflect the strategy of using SMBG as part of usual care and one of the practices encouraged through health education program implemented to achieve glycemic control in this center.

Neither gender nor age found to be related to the frequency of SMBG utilization while in a study of $>44$ managed care patients with type 1 and type 2 DM, Karter et al. (2000) identified older age, male gender as independent predictors of less frequent self monitoring in diabetic patients, might be explained by the differences in the attitude and motivation provided for diabetic patients among different societies toward using SMBG.

Lower rates of SMBG were correlated with having less than secondary or higher education found to be consistent with findings from other studies, the negative association between SMBG and lower education suggest that socioeconomic barriers might impede the practice of SMBG (Harris et al., 1993; Adams et al., 2003).

In a study conducted in eastern Massachsetts in Boston, Adams et al. (2003) conclude that insulin 
managed patients were more likely to self monitor compared to those using oral medications which was not evident in the present study since SMBG reported by the interviewer might be underestimated or overestimated since it subjected to recall bias.

The aim of using SMBG is to improve glycemic control to lower $\mathrm{HbAl} \mathrm{c}$ and ultimately reduced long term complications (Martin et al., 2006), the similarity in the mean level of HbA1C among participants in this study associated with frequency of SMBG and regardless of the line of treatment among type 2 diabetes which was also evident in other studies Both cross-sectional and longitudinal fermantle diabetes study (Davis et al., 2006) showed that $\mathrm{HbAlc}$ was not significantly different between SMBG users and non users, neither SMBG testing nor it's frequency was associated with glycemic benefits in type 2 diabetes patients regardless of treatment (Davis et al., 2006) on the other hand a prospective randomized controlled trial in Ireland (ESMON study) (O'Kane et al., 2008) concluded that SMBG in people with newly diagnosed type 2 diabetes gave no advantage in improvement in glycemic control compared with those did not monitor ( $\mathrm{O}^{\prime} \mathrm{Kane}$ et al., 2008). While benefits of SMBG in the management of patients with type 2 diabetes not receiving insulin have been observed in the Kaiser Permanent Northern California Medical Care Program and the ROSSO study (Martin et al., 2006; Kolb et al., 2007) and in a meta analys is study of 1307 non insulin treated patients with type 2 diabetes demonstrated a $0.42 \%$ lower $\mathrm{HbAl}$ c level in those patients who performed SMBG as compared to those who did not apply (Schnell and Heinemann, 2007).

Although, many studies have reported negative findings regarding SMBG in non insulin treated diabetes (Parkin and Price, 2007; Davidson et al., 2005), optimal SMBG use requires that both patients and health care professionals monitor, interpret and respond appropriately to acute glucose excursions and patterns of glycemia identified through SMBG (Parkin and Price, 2007; Klonoff, 2008; Austin et al., 2006).

Failure to have benefit from SMBG use in noninsulin treated diabetes may stem from a misapplication or misunderstanding of true utility of SMBG as a tool to guide therapy rather than an independent therapeutic intervention (Parkin and Price, 2007; Klonoff, 2008; Parkin and Hirsch, 2005).

The key to effective use of SMBG in clinical practice is pattern analysis which is a systematic approach to identifying glycemic patterns within SMBG data and when taking appropriate action based upon those results (Dailey, 2007), the availability of computer based and paper based data collection and management tools facilitates more robust and efficient use of SMBG data allowing clinicians and patients to quickly identify glycemic patterns and make more informed decisions about therapeutic adjustments that may be required (Parkin and Davidson, 2009).

\section{CONCLUSION}

SMBG remains one of effective and easily handled tool that reflect the awareness of diabetic patients toward the sequel of uncontrolled hypeglycemia. To optimize the benefit of utilizing SMBG and to render it to a cost benefit regimen requires intensified diabetes education program carried by the specialized centers of diabetes to lead the patients for the optimal timing and frequency of self monitoring and how to interpret and response to the results correctly by precise adjustment of their diet, exercise and medicine. Such programs can be followed by further studies to monitor the effectiveness of SMBG.

\section{REFERENCES}

Adams, A.S., C. Mah, S.B. Soumerai, F. Zhang, M.B. Barton and D. Ross-Degnan, 2003. Barriers to self-monitoring of blood glucose among adults with diabetes in an HMO: A cross sectional study. BMC Health Services Res., 3: 6-6.

American Diabetes Association, 2002. Clinical practice recommendations 2001: Standards of medical care for patients with diabetes. Diabetes Care, 24: 533-550.

American Diabetes Association, 2007. Standards of medical care in diabetes-2007. Diabetes Care, 30: 4-41.

Austin, M.M., L. Haas, T. Johnson, C.G. Parkin, C.L. Parkin, G. Spollett and M.T. Volpone, 2006. Self-monitoring of blood glucose: Benefits and utilization. Diabetes Educ., 32: 835-836-844-847.

Dailey, G., 2007. Assessing glycemic control with self-monitoring of blood glucose and hemoglobin A(1c) measurements. Myo Clin. Proc., 82: 229-235.

Davidson, M.B., M. Castellanos, D. Kain and P. Duran, 2005. The effect of self monitoring of blood glucose concentrations on glycated hemoglobin levels in diabetic patients not taking insulin: A blinded, randomized trial. Am. J. Med., 118: 422-425.

Davis, W.A., D.G. Bruce and T.M. Davis, 2006. Is self-monitoring of blood glucose appropriate for all type 2 diabetic patients: The fremantle diabetes study. Diabetes Care, 29: 1764-1770.

Derr, R., E. Garrett, G.A. Stacy and C.D. Saudek, 2003. Is $\mathrm{HbAlc}$ affected by glycemic instability. Diabetes Care, 26: 2728-2733. 
Harris, M.I., C.C. Cowie and L.J. Howie, 1993. Selfmonitoring of blood glucose by adults with diabetes in the United States population. Diabetes Care, 16: 1116-1123.

Karter, A.J., A. Ferrara, J.A. Darbinian, L.M. Ackerson and J.V. Selby, 2000. Self-monitoring of blood glucose: Language and financial barriers in a managed care population with diabetes. Diabetes Care, 23: 477-483.

Karter, A.J., M.M. Parker, H.H. Moffet, M.M. Spence, J. Chan, S.L. Ettner and J.V. Selby, 2006. Longitudinal study of new and prevalent use of self-monitoring of blood glucose. Diabetes Care, 29: 1757-1763.

Klonoff, D.C., 2008. New evidence demonstrates that self-monitoring of blood glucose does not improve outcomes in type 2 diabetes-when this practice is not applied properly. J. Diabetes Sci. Technol., 2: 342-348.

Kolb, H., B. Schneider, L. Heinemann, V. Lodwig, W.A. Scherbaum and S. Martin, 2007. Altered disease course after initiation of self-monitoring of blood glucose in noninsulin-treated type 2 diabetes (ROSSO 3). J. Diabetes Sci. Technol., 1: 487-495.

Martin, S., B. Schneider, L. Heinemann, V. Lodwig and H.J. Kurth et al., 2006. Self-monitoring of blood glucose in type 2 diabetes and long-term outcome: An epidemiological cohort study. Diabetologia, 49: 271-278.
O'Kane, M.J., B. Bunting, M. Copeland, V.E. Coates and ESMON Study Group, 2008. Efficacy of self monitoring of blood glucose in patients with newly diagnosed type 2 diabetes (ESMON study): Randomised controlled trial. Br. Med. J., 336: 1174-1177.

Palmer, A.J., S. Dinneen, J.R. Gavin, A. Gray, W.H. Herman and A.J. Karter, 2006. Cost-utility analysis in a UK setting of self-monitoring of blood glucose in patients with type 2 diabetes. Curr. Med. Res. Opin., 22: 861-872.

Parkin, C.G. and D. Price, 2007. Randomized studies are needed to assess the true role of self-monitoring of blood glucose in noninsulin-treated type 2 diabetes. J. Diabetes Sci. Technol., 1: 595-602.

Parkin, C.G. and I.B. Hirsch, 2005. Self-monitoring of blood glucose cannot compensate for ineffective diabetes management. Am. J. Med., 118: 1448-1449.

Parkin, C.G. and J.A. Davidson, 2009. Value of selfmonitoring blood glucose pattern analysis in improving diabetes outcomes. J. Diabetes Sci. Technol., 3: 500-508.

Schnell, O. and L. Heinemann, 2007. Self-monitoring of blood glucose in noninsulin-treated patients with type 2 diabetes: A never ending story. J. Diabetes Sci. Technol., 1: 614-616. 